\title{
Community mental healthcare for people with severe personality disorder: narrative review
}

\author{
Bauke Koekkoek, ${ }^{1}$ Berno van Meijel, ${ }^{2}$ Giel Hutschemaekers ${ }^{3}$
}

The Psychiatrist (2010), 34, 24-30, doi: 10.1192/pb.bp.108.022426

${ }^{1}$ Altrecht Mental Health Care,

The Netherlands; ${ }^{2}$ Inholland University,

Amsterdam, The Netherlands:

${ }^{3}$ Gelderse Roos Mental Health

Care and Radboud University,

The Netherlands

Correspondence to Bauke Koekkoek (b.koekkoek@altrecht.nl)

\begin{abstract}
Aims and method To assess the contents and the theoretical and empirical base of community mental healthcare $(\mathrm{CMHC})$ for people with severe personality disorder. Medline and PsycINFO databases and handbooks were searched from 1980, as well as a recent meta-analysis and systematic review of trials in which $\mathrm{CMHC}$ served as the control condition.

Results Community mental healthcare is a long-term community-based treatment within a supportive atmosphere, aimed at stability rather than change. Mostly offered by community psychiatric nurses, occupational therapists and social workers, it lacks a formal structure, as well as theoretical underpinnings that guide interventions.
\end{abstract}

Clinical implications Community mental healthcare might profit from a more systematic application of effective ingredients from other treatments.

Declaration of interest None.
People with severe personality disorders do not easily find their way into treatment. ${ }^{1}$ Many may go unnoticed owing to limited detection by health providers, ${ }^{2}$ resulting in patients not receiving specialised therapy. ${ }^{3-5}$ Even when such increasingly effective therapies are indicated, ${ }^{6-7}$ not all patients profit from them because of limited availability or suitability. Apart from notable differences in their implementation, our own experience with referral to and working in these specialised therapies is that in many cases the therapies are not indicated or the patients fail to enter treatment, drop out or fail to improve. Some patients have limited motivation or capacities, have an abundance of social problems that prevent therapy taking place properly, behave in an overly disruptive manner or lack the stability to attend sessions regularly. In a large group of patients with severe personality disorders, those of lower socioeconomic status and with more impaired psychosocial functioning were more likely to receive residential, day and psychopharmacological treatment than intensive individual, couple or group psychotherapy. ${ }^{8}$

A general form of treatment may then be offered to these patients: community mental healthcare (CMHC). This is a community-based, long-term treatment within a supportive atmosphere aimed at stability rather than change. Although referred to as 'good clinical care,', it is largely unclear if CMHC is 'good'. On the contrary, in daily practice it is often associated with long-term care lacking clear aims and therapeutic ambitions, ${ }^{10}$ possibly resulting in unnecessary dependency. In addition, negative professional attitudes towards patients with personality disorders have been reported frequently, ${ }^{11-13}$ possibly resulting in an ineffective patient-professional interaction, especially in long-term supportive care. Therefore, we aim to answer the following questions in this review: what, exactly, is CMHC for severe personality disorder; who provides it; how does it compare with other forms of treatment for this disorder; what are its empirical and theoretical underpinnings; and what are its strengths and limitations?

\section{Method}

The search strategy consisted of three successive phases, owing to limited findings in the previous phases. First, a systematic search of general databases was conducted. Second, control conditions of experimental treatments of personality disorder treatments were searched. Third, textbooks and cross-references were used to obtain a broader scope.

A search of the Medline and PsycINFO databases was conducted for publications in English between 1980 (when Axis II was introduced in the DSM-III) and May 2006. Owing to the lack of a clear search term for CMHC, a broad search strategy was designed. The MeSH headings 'personality disorders' AND ('community mental health service' OR 'counseling' OR 'ambulatory care' OR 'nursing care' OR 'long-term care' OR 'case management' OR 'social work' OR 'psychiatric social work' OR 'day care' OR 'rehabilitation' OR 'supportive therapy' [the last as a title word]) were used. The main inclusion criteria were that the article had to have a psychosocial treatment of personality disorders as its main subject and be written in English. Exclusion criteria were descriptions or evaluations of manualised specialised psychotherapy for personality disorder; interventions with juveniles (under 18 years old) or those over 65 years of age; and interventions in a non-psychiatric setting (e.g. a general hospital). Although over a thousand references were 
retrieved, only 20 met these criteria. For this reason, an additional search strategy was designed. A meta-analysis of psychotherapy outcomes for personality disorders and a recent Cochrane systematic review of psychotherapies for borderline personality disorder were analysed to detect studies that possibly described $\mathrm{CMHC}$ as the control condition., $^{1,2}$ No other more recent meta-analyses or Cochrane reviews of this field were available at the time this search took place.

Of the total 26 studies analysed, 7 described the control condition ('treatment as usual') in enough detail to be of use. The remaining 19 studies did not aim at severe personality disorder, did not have a control condition, described a second psychotherapeutic treatment as the control condition or described the control condition only vaguely. Since these control conditions were only described and not explained in detail, we hand-searched recent textbooks on personality disorders - retrieved on the internet by combining 'personality disorders' with 'management' and ('handbook' or 'textbook' or 'guide' or 'manual') - for chapters or texts on non-psychotherapeutic treatments. Additionally, we used cross-references to extend findings and broaden our understanding of the subject.

\section{Results}

In the search conducted, no single paper was devoted to the description of what might be considered as standard community care for severe personality disorder. Our additional search strategy yielded eight descriptions of 'treatment as usual' (Table 1), ${ }^{14-21}$ based on which we draw some tentative conclusions. Community mental healthcare is most often offered on an out-patient basis, every 2 weeks on average, lasting 6-24 months. It is not formalised or manualised but consists of an eclectic mix of different modalities. It has a supportive character that seems more closely linked to care and psychosocial support than to psychotherapy. It is most often offered by general mental health professionals (not psychotherapists). Formal goals of CMHC are not acknowledged in the literature retrieved, yet they seem to be centred around not making things worse, offering a certain holding to the patient and keeping things under control. ${ }^{9}$ It appears relatively universal across Western psychiatry, since studies originated from different parts of the world (Australia, Europe and North America).

\section{Professionals providing community mental healthcare}

From a number of studies we may tentatively conclude that mental health professionals from different backgrounds, without formal psychotherapeutic training, offer $\mathrm{CMHC}^{14-21}$ This would be consistent with daily practice noticed in different countries, where care is offered from busy nonspecialised mental health centres. ${ }^{3,22}$ From an English study it was concluded that the case-loads of community psychiatric nurses and occupational therapists in community mental health teams contained far more patients with

\begin{tabular}{|c|c|c|c|c|c|c|}
\hline $\begin{array}{l}\text { Researchers } \\
\text { (country, } \\
\text { publication year) }\end{array}$ & $\begin{array}{l}\text { Experimental } \\
\text { condition }\end{array}$ & Control condition & Location & Profession & Duration & Frequency \\
\hline $\begin{array}{l}\text { Woody et al }{ }^{14} \\
\text { (USA, 1985) }\end{array}$ & $\begin{array}{l}\text { Drug counselling } \\
\text { and manualised } \\
\text { psychotherapy }\end{array}$ & Drug counselling & Out-patient & $\begin{array}{l}\text { Mental health } \\
\text { professionals }\end{array}$ & $\begin{array}{l}\text { Not } \\
\text { known }\end{array}$ & $\begin{array}{l}\text { Not } \\
\text { known }\end{array}$ \\
\hline $\begin{array}{l}\text { Linehan et all } \\
\text { (USA, 1991) }\end{array}$ & $\begin{array}{l}\text { Dialectical } \\
\text { behaviour therapy }\end{array}$ & $\begin{array}{l}\text { Non-manualised } \\
\text { psychotherapy or alternative } \\
\text { therapy }\end{array}$ & Out-patient & Not known & $>1$ year & $\begin{array}{l}\text { Not } \\
\text { known }\end{array}$ \\
\hline $\begin{array}{l}\text { Stevenson \& } \\
\text { Meares } \\
\text { (Australia, 1992) }\end{array}$ & $\begin{array}{l}\text { Self-psychology } \\
\text { psychotherapy }\end{array}$ & $\begin{array}{l}\text { Crisis intervention, supportive } \\
\text { psychotherapy, cognitive } \\
\text { therapy and/or } \\
\text { pharmacotherapy (all } \\
\text { non-manualised) }\end{array}$ & Out-patient & Not known & 12 months & $\begin{array}{l}\text { Not } \\
\text { known }\end{array}$ \\
\hline $\begin{array}{l}\text { Bateman \& Fonagy }{ }^{17} \\
(\text { UK, 1999) }\end{array}$ & $\begin{array}{l}\text { Mentalisation-based } \\
\text { treatment }\end{array}$ & $\begin{array}{l}\text { Pharmacotherapy (partial), } \\
\text { hospitalisation and supportive } \\
\text { out-patient and community } \\
\text { care }\end{array}$ & $\begin{array}{l}\text { (Day) } \\
\text { hospital and } \\
\text { out-patient }\end{array}$ & $\begin{array}{l}\text { Community } \\
\text { psychiatric } \\
\text { nurse and } \\
\text { psychiatrist }\end{array}$ & $>6$ months & $\begin{array}{l}\text { Every } \\
2 \text { weeks }\end{array}$ \\
\hline $\begin{array}{l}\text { Linehan et al }{ }^{18} \\
\text { (USA, 1999) }\end{array}$ & $\begin{array}{l}\text { Dialectical } \\
\text { behaviour therapy }\end{array}$ & $\begin{array}{l}\text { Non-manualised } \\
\text { psychotherapy, counselling } \\
\text { or case management }\end{array}$ & Out-patient & $\begin{array}{l}\text { Mental health } \\
\text { professionals }\end{array}$ & 12 months & $\begin{array}{l}\text { As } \\
\text { required }\end{array}$ \\
\hline $\begin{array}{l}\text { Koons et al }{ }^{19} \\
\text { (USA, 2001) }\end{array}$ & $\begin{array}{l}\text { Dialectical } \\
\text { behaviour therapy }\end{array}$ & $\begin{array}{l}\text { Non-manualised } \\
\text { psychotherapy, supportive } \\
\text { and psychoeducational groups }\end{array}$ & Out-patient & Not known & 6 months & Weekly \\
\hline $\begin{array}{l}\text { van den Bosch et al } \\
\text { (The } \\
\text { Netherlands, 2002) }\end{array}$ & $\begin{array}{l}\text { Dialectical } \\
\text { behaviour therapy }\end{array}$ & Clinical management & Out-patient & $\begin{array}{l}\text { Psychiatrist, } \\
\text { psychologist or } \\
\text { social worker }\end{array}$ & 12 months & $\begin{array}{l}\text { Every } 2 \\
\text { weeks or } \\
\text { less often }\end{array}$ \\
\hline $\begin{array}{l}\text { Chiesa \& Fonagy }{ }^{21} \\
\text { (UK, 2004) }\end{array}$ & $\begin{array}{l}\text { Psychoanalytic } \\
\text { (partial) hospital } \\
\text { and out-patient } \\
\text { treatment }\end{array}$ & $\begin{array}{l}\text { Pharmacotherapy, supportive } \\
\text { out-patient and community } \\
\text { care, clinical review and } \\
\text { hospitalisation (as needed) }\end{array}$ & $\begin{array}{l}\text { Hospital and } \\
\text { out-patient }\end{array}$ & Care workers & 24 months & $\begin{array}{l}\text { Every } \\
2-4 \text { weeks }\end{array}$ \\
\hline
\end{tabular}


personality disorders (67\%) than did those of psychiatrists and psychologists $(35 \%) .{ }^{23}$ In a comparable study, it was social workers and again occupational therapists who treated most people with personality disorder. ${ }^{24}$ A possible explanation is that patients with severe personality disorders are treated by the professionals with the lowest threshold for inclusion in their case-load (i.e. nonpsychotherapists). Support for this hypothesis is offered by the large percentage of patients with severe personality disorders among the case-loads of community psychiatric nurses and occupational therapists: twice as many as among psychiatrists and psychologists $\left(31 \%\right.$ v. 15\%). ${ }^{23}$ Although these professions may be the principal providers of CMHC, they are virtually absent from the literature on severe personality disorders (e.g. in a guide on personality disorders and community mental health teams, they did not author a single chapter). ${ }^{25}$

\section{Relation to other treatments}

We conclude from the above that CMHC is an eclectic treatment, combining elements of different therapeutic approaches (especially cognitive-behavioural and supportive therapy), crisis management and pharmacotherapy. It resembles the 'psychiatric management' described in the American Psychiatric Association's guideline on borderline personality disorder. ${ }^{26}$ Its principles are:

- responding to crises and monitoring safety;

- establishing and maintaining a therapeutic framework and alliance;

- providing education about the disorder and its treatment;

- coordinating the treatment effort;

- monitoring and reassessing the patient's clinical status and treatment plan.

However structured this may look, no treatment form is described as such and in daily practice decisions may be made on a much more ad hoc basis.

Community mental healthcare differs from psychotherapy and psychosocial rehabilitation in several ways (Table 2). The distinct empirically supported psychotherapies focus on internal psychological processes such as increased emotion regulation (dialectical behaviour therapy), ${ }^{15}$ change of maladaptive schemas (schema-focused therapy), ${ }^{27}$ increased mentalisation (mentalisation-based therapy), ${ }^{17}$ or integration of internal mental representations (transferencefocused therapy). ${ }^{28}$ If $\mathrm{CMHC}$ is carefully and successfully carried out, patients may move on to one of these programmes, if available. ${ }^{29}$ Psychosocial rehabilitation programmes, on the other hand, focus more on social functioning and aim at increased social participation and activities. Originally designed for people with psychotic disorders, rehabilitative approaches are described increasingly frequently in cases of personality disorder. From different international perspectives, a professional attitude of acceptance of, and coping with, chronic problems is described. ${ }^{30-34}$ The extension of psychosocial rehabilitation to this group of patients is not without trouble, however. Many professionals do not know how to work well with these patients: they find the working alliance with patients with personality disorders more complex than with patients with psychosis (who mostly receive psychosocial rehabilitation). ${ }^{34}$ Likewise, people with

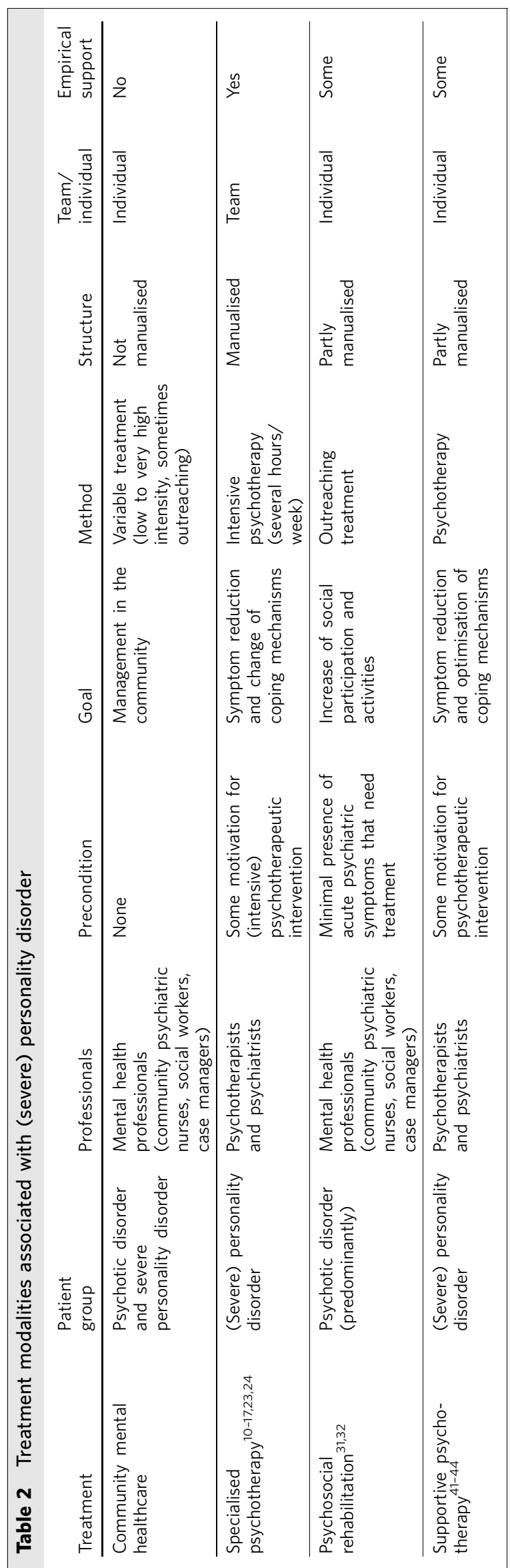


(severe) personality disorder as a primary diagnosis are rarely represented in psychosocial rehabilitation or assertive community treatment programmes, ${ }^{35-37}$ or are more likely to drop out. ${ }^{38}$

In textbooks on personality disorders, some treatment elements (although not CMHC in general) are described in more detail: psychoeducational approaches, ${ }^{39,40}$ supportive therapy, ${ }^{41,42}$ and general treatment considerations. ${ }^{43,44}$ Supportive psychotherapy, which aims at adaptation (a concept discussed below in more detail) is the most researched of these. ${ }^{4-47}$ Some empirical support exists for it in general, ${ }^{48,49}$ and for cluster $\mathrm{B}$ and $\mathrm{C}$ personality disorders in particular. $^{46,47}$ Some authors suggest that supportive therapy might be the treatment of choice with patients with severe personality disorders. ${ }^{41,45,46}$ Other studies emphasise the adaptive element in the treatment of severe personality disorder and offer some instructions on specific areas: adjusting environmental factors, ${ }^{50,51}$ offering vocational training, ${ }^{52}$ and installing supportive milieus. ${ }^{53}$ Practical matters such as the optimal frequency of appointments, managing 'no-show' and indication criteria for hospitalisation are not addressed in either approach.

\section{Theoretical and empirical base of community mental healthcare}

The aforementioned issues may be resolved through the use of a theoretical framework, yet none of the articles retrieved contained any data about theoretical or empirical support for CMHC. Although the supportive therapy mentioned above differs significantly from $\mathrm{CMHC}$ in that it is more formalised and strict (e.g. weekly appointments for a given number of weeks) and requires at least some motivation for a change-oriented treatment, its theoretical concept may apply to CMHC as well. The theoretical base of supportive therapy lies in an adaptive concept: the therapist ensures the safety of the patient by being non-judgemental, by supporting effective defence mechanisms, by focusing on the real relationship instead of on transference phenomena, and by reframing negative experiences into more positive meanings. Transference is then analysed only when it obstructs treatment. This description, although not derived from the CMHC literature, fits in with our previous general description of CMHC, as well as with aforementioned adaptive approaches. Community mental healthcare offers a supportive rather than a confrontational atmosphere and also focuses on the 'here and now'. The difference lies in its final aim, which in supportive therapy is individual change, whereas in $\mathrm{CMHC}$ it is management in the community and preservation of a certain quality of life.

\section{Strengths and limitations of community mental healthcare}

Community mental healthcare may be regarded as a highly humane form of help for particularly vulnerable individuals, as expressed through the term 'good clinical care'. ${ }^{3,9}$ For example, patients who are frequently (para)suicidal are usually not welcome in other branches of social or mental healthcare, thus CMHC may be the only service that supports these patients. It may be argued that if these patients could not seek some refuge in mental healthcare they would become marginalised even further. The validity of this argument is somewhat undermined by recent data on the natural course of borderline personality disorder. This research, showing diminishing symptoms over a 10-year period, ${ }^{54}$ suggests that intrusive interventions by mental health professionals may not always be indicated. Also, rapid remissions that could not be completely related to treatment gains have been seen in some patients with borderline personality disorder. ${ }^{55}$ However, in neither of these studies could the positive (or negative) attributions of therapy to remission be assessed empirically. Although treatment is obviously helpful in most cases, it cannot be concluded that treatment is always necessary or better than no treatment.

\section{Discussion}

First of all, we must state that this review has some limitations: we are not sure to what extent the indirect information about $\mathrm{CMHC}$ is reliable. It may be that $\mathrm{CMHC}$ is very different from setting to setting and even from professional to professional. Another limitation is the lack of differentiation between the accessibility of different systems of psychiatric care across Western countries. Because of local funding principles, CMHC may be quite inclusive in some regions and virtually absent in others. Although we know from personal experience and intercollegiate contacts that these differences exist, we could not trace them in the literature. Owing to the limited literature and even more limited research, the conclusions of this review must be considered as preliminary.

From our results we conclude that $\mathrm{CMHC}$ lacks a clear description and both solid empirical and theoretical grounds. The lack of evidence does in itself not mean that $\mathrm{CMHC}$ has no relevance or quality, but does make it susceptible to debate. Since CMHC has only served as a control condition in research thus far, it has not been established for whom and when it may work. The studies reviewed here show different outcomes: both positive and negative as well as undecided or hard to interpret. As such, we cannot be definitive about CMHC apart from the observation that a treatment that appears to be harmful in some cases needs to be indicated carefully. Once indicated, we believe $\mathrm{CMHC}$ would profit from meeting some basic requirements.

\section{latrogenic damage}

The main argument to consider carefully when assessing the suitability of CMHC for patients with severe personality disorder is the risk of iatrogenic damage, opposed to the chance of (sometimes spontaneous) remission. Current opinion is that people with the single most prominent personality disorder (borderline) do not always profit more from bad care than from no care at all. ${ }^{52-54}$ Community mental healthcare, which could potentially be provided 'several times a week' (Dowson \& Grounds: ${ }^{9}$ p. 276) 'on an indefinite basis' (ibid: p. 278) may foster unnecessary dependence on psychiatric care in the patient. ${ }^{9}$ Iatrogenic damage may also consist of serious (physical) damage from multiple or lengthy hospitalisations aimed at preventing suicide, yet paradoxically exacerbating it. ${ }^{59}$ Such damage is observed more often in $\mathrm{CMHC}$ than in specialised care. ${ }^{60}$ 
With regard to other personality disorders, equal doubts about the need for support and the risk of dependency have been expressed. ${ }^{22,44}$ If some patients actually become worse through CMHC, its indication for any patient should be carefully considered. Moreover, owing to the often turbulent course of treatment and the difficulties of the patients involved, interpersonal problems between patients and professionals easily arise in CMHC. As staff members are not always specifically trained in the management of such (counter)transference, and community mental health centres tend to be busy and somewhat overburdened institutions, ${ }^{25,61-63}$ adverse reactions are likely. In particular, staff who primarily work with major Axis I disorders (e.g. psychotic disorders, in which interpersonal issues are of a different kind) may be unpleasantly surprised by the impact of working with people with severe personality disorder. ${ }^{60}$ The centre's structure and culture may not be prepared for intensive supervision or consultation with regard to these patients.

\section{Possible improvements}

Community mental healthcare would, in our view, greatly benefit from some alterations. First, it should have a solid structure. The current practice of intermittent reinforcement of intensive crisis intervention, combined with relatively little or no care during calmer periods, may be the very perpetuator of the dependency loathed by many (e.g. British psychiatrists who recently stated that patients may expect more than just 'non-specific psychosocial support'). ${ }^{10}$ Improvement of the structure and predictability (including, for instance, mutual goal-setting, treatment contracting and limit-setting) of CMHC might prevent this. Second, from two highly researched psychotherapies for severe borderline personality disorder (dialectical behaviour therapy and mentalisation-based therapy) it may be concluded that a team approach is preferable to an individual one. In such a cooperative framework, it is highly important that professionals working with patients with severe personality disorders are in some way able to express their feelings about patient contacts. Although hardly surprising, and obviously relevant for any form of treatment for personality disorders, this is often overlooked in CMHC. Professionals providing CMHC are often not psychotherapeutically trained and may lack the routine of looking at their own role in the therapeutic encounter. ${ }^{65}$ Therefore, supervision should be provided within the (treatment) structure of the team. ${ }^{66}$ Third, not every individual is suited to work with people with severe personality disorder. Gunderson et al concluded, having studied 752 clinicians, that 'some psychiatrists, many social workers and most nurses' consider themselves incompetent with patients with borderline disorder (p. 248). ${ }^{29}$ Considering that $\mathrm{CMHC}$ is often provided by social workers and community psychiatric nurses, assigning patients with severe personality disorder at random to a community mental health professional may be unwise. Awareness of each team member's abilities and limitations may help in such cases. Furthermore, research shows that training may be effective in improving both professionals' knowledge of these patients and their attitudes towards them. ${ }^{67,68}$

\section{Implications for research and practice}

Although our results are limited in both quantity and quality, we may draw some preliminary conclusions from this review. Community mental healthcare may profit from more structure than it currently has. It should not ignore social problems, while maintaining a working alliance that fosters clients' independence and responsibility. A team approach that enables mutual support and supervision and matches patients to professionals might further improve quality, just as focused training might do. An integration of useful elements of specialised psychotherapy and psychosocial rehabilitation might serve CMHC well. Such an integrative programme should combine the specific elements of the former (e.g. management of patient-professional interaction, explanatory model of personality disorders) with those of the latter (e.g. long-term goal-setting, strategies to enhance social participation).

\section{Funding}

This study was made possible by financial support from ZonMw (Geestkracht program, grant 100-002-031), Altrecht Mental Health Care, De Gelderse Roos Mental Health Care and Inholland University, Amsterdam, The Netherlands.

\section{About the authors}

Bauke Koekkoek is a Registered Nurse, Community Psychiatric Nurse and Researcher at the Department of Community Care Zeist, Altrecht Mental Health Care, and Institute for Professionalisation at Gelderse Roos Mental Health Care, Wolfheze, The Netherlands. Berno van Meijel is a Registered Nurse and Associate Professor, Research Group Mental Health Nursing, Inholland University, Amsterdam, The Netherlands. Giel Hutschemaekers is Director, Institute for Professionalisation at Gelderse Roos Mental Health Care, Wolfheze, and Professor of Clinical Psychology, Academic Centre of Social Sciences, Radboud University, Nijmegen, The Netherlands.

\section{References}

1 Bateman AW, Tyrer P. Services for personality disorder: organisation for inclusion. Adv Psychiatr Treat 2004; 10: 425-33.

2 Links PS, Boiago I, Allnut S. Understanding and recognizing personality disorders. In Clinical Assessment and Management of Severe Personality Disorders (ed PS Links): 1-20. American Psychiatric Publishing, 1996.

3 Andrews G. The essential psychotherapies. Br J Psychiatry 1993; 162: 447-51.

4 Stone $\mathrm{MH}$. Personality-disordered Patients. Treatable and Untreatable. American Psychiatric Publishing, 2005

5 Adshead G. Murmurs of discontent: treatment and treatability of personality disorder. Adv Psychiatr Treat 2001; 7: 407-15.

6 Leichsenring $F$, Leibing $E$. The effectiveness of psychodynamic therapy and cognitive behaviour therapy in the treatment of personality disorders: a meta-analysis. Am J Psychiatry 2003; 160: 1223-32.

7 Binks CA, Fenton M, McCarthy L, Lee T, Adams CE, Duggan C. Psychological therapies for people with borderline personality disorder. Cochrane Database Syst Rev 2006; issue 1: CD005652.

8 Zanarini MC, Frankenburg FR, Hennen J, Silk KR. Mental health service utilization by borderline personality disorder patients and Axis II comparison subjects followed prospectively for 6 years. J Clin Psychiatry 2004; 65: 28-36.

9 Dowson JH, Grounds A. Personality Disorder: Recognition and Clinical Management. Cambridge University Press, 1995. 
10 Craddock N, Antebi D, Attenburrow MJ, Bailey A, Carson A, Cowen P, et al. Wake-up call for British psychiatry. Br J Psychiatry 2008; 193: 6-9.

11 Lewis G, Appleby L. Personality disorder: the patients psychiatrists dislike. Br J Psychiatry 1988; 153: 44-9.

12 Deans C, Meocevic E. Attitudes of registered psychiatric nurses towards patients diagnosed with borderline personality disorder. Contemp Nurse 2006; 21: 43-9.

13 Newton-Howes G, Weaver T, Tyrer P. Attitudes of staff towards patients with personality disorder in community mental health teams. Aust N Z J Psychiatry 2008; 42: 572-7.

14 Woody GE, McLellan AT, Luborsky L, O'Brien CP. Sociopathy and psychotherapy outcome. Arch Gen Psychiatry 1985; 42: 1081-6.

15 Linehan MM, Armstrong HE, Suarez A, Allmon D, Heard HL. Cognitivebehavioural treatment of chronically parasuicidal borderline patients. Arch Gen Psychiatry 1991; 48: 1060-4.

16 Stevenson J, Meares R. An outcome study of psychotherapy for patients with borderline personality disorder. Am J Psychiatry 1992; 149: 358-62

17 Bateman A, Fonagy P. Effectiveness of partial hospitalization in the treatment of borderline personality disorder: a randomized controlled trial. Am J Psychiatry 1999; 156: 1563-9.

18 Linehan MM, Schmidt H, Dimeff LA, Craft JC, Kanter J, Comtois KA Dialectical behaviour therapy for patients with borderline personality disorder and drug-dependence. Am J Addict 1999; 8: 279-92.

19 Koons CR, Robins CJ, Tweed JL, Lynch TR, Gonzalez AM, Morse JQ, et al. Efficacy of dialectical behaviour therapy in women veterans with borderline personality disorder. Behav Ther 2001; 32: 371-90.

20 van den Bosch LM, Verheul R, Schippers GM, van den Brink W Dialectical Behaviour Therapy of borderline patients with and without substance use problems. Implementation and long-term effects. Addict Behav 2002; 27: 911-23.

21 Chiesa M, Fonagy $P$, Holmes J, Drahorad C. Residential versus community treatment of personality disorders: a comparative study of three treatment programs. Am J Psychiatry 2004; 161: 1463-70.

22 Burns T. An introduction to community mental health teams (CMHTs) how do they relate to patients with personality disorders? In Personality Disorder and Community Mental Health Teams: A Practitioner's Guide (eds M Sampson, R McCubbin, P Tyrer). Wiley, 2006.

23 Keown P, Holloway F, Kuipers E. The prevalence of personality disorders, psychotic disorders and affective disorders amongst the patients seen by a community mental health team in London. Soc Psychiatry Psychiatr Epidemiol 2002; 37: 225-9.

24 Greenwood N, Chisholm B, Burns T, Harvey K. Community mental health team case-loads and diagnostic case-mix. Psychiatr Bull 2000; 24: $290-3$

25 Sampson M, McCubbin R, Tyrer P (eds). Personality Disorder and Community Mental Health Teams: A Practitioner's Guide. Wiley, 2006.

26 American Psychiatric Association. Practice guideline for the treatment of patients with borderline personality disorder. Am J Psychiatry 2001; 158 (suppl): 1-52.

27 Giesen-Bloo J, van Dyck R, Spinhoven P, van Tilburg W, Dirksen C, van Asselt $\mathrm{T}$, et al. Outpatient psychotherapy for borderline personality disorder: randomized trial of schema-focused therapy vs transferencefocused psychotherapy. Arch Gen Psychiatry 2006; 63: 649-58.

28 Clarkin JF, Levy KN, Lenzenweger MF, Kernberg OF. Evaluating three treatments for borderline personality disorder: a multiwave study. Am $J$ Psychiatry 2007; 164: 922-8.

29 Gunderson JG, Gratz KL, Neuhaus EC, Smith GW. Levels of care in treatment. In Textbook of Personality Disorders (eds JM Oldham, AE Skodol, DS Bender): 239-48. American Psychiatric Publishing, 2005.

30 Livesley WJ. Changing ideas about the treatment of borderline personality disorder. J Contemp Psychother 2004; 34: 185-92.

31 Paris J. Personality disorders over time: precursors, course and outcome. J Personal Disord 2003; 17: 479-88.

32 Links PS. Psychiatric rehabilitation model for borderline personality disorder. Can J Psychiatry 1993; 38 (suppl 1): S35-8.
33 Krawitz R, Watson C. Borderline Personality Disorder: A Practical Guide to Treatment. Oxford University Press, 2003.

34 Nehls N. Being a case manager for persons with borderline personality disorder: perspectives of community mental health center clinicians. Arch Psychiatr Nurs 2000; 14: 12-8.

35 Barton R. Psychosocial rehabilitation services in community support systems: a review of outcomes and policy recommendations. Psychiatr Serv 1999; 50: 525-34.

36 Twamley EW, Jeste DV, Lehman AF. Vocational rehabilitation in schizophrenia and other psychotic disorders: a literature review and meta-analysis of randomized controlled trials. J Nerv Ment Dis 2003; 191: $515-23$

37 Ranger M, Methuen C, Rutter D, Rao B, Tyrer P. Prevalence of personality disorder in the case-load of an inner-city assertive outreach team. Psychiatr Bull 2004; 28: 441-3.

38 Cohen K, Edstrom K, Smith-Papke L. Identifying early dropouts from a rehabilitation program for psychiatric outpatients. Psychiatr Serv 1995; 46: $1076-8$

39 Ruiz-Sancho AM, Smith GW, Gunderson JG. Psychoeducational approaches. In Handbook of Personality Disorders: Theory, Research and Treatment (ed WJ Livesley): 460-74. Guilford, 2001.

40 Hoffman PD, Fruzetti AE. Psychoeducation. In Textbook of Personality Disorders (eds JM Oldham, AE Skodol, DS Bender): 375-86. American Psychiatric Publishing, 2005

41 Winston A, Rosenthal RN, Muran JC. Supportive psychotherapy. In Handbook of Personality Disorders: Theory, Research and Treatment (ed WJ Livesley): 344-58. Guilford, 2001.

42 Appelbaum A. Supportive psychotherapy. In Textbook of Personality Disorders (eds JM Oldham, AE Skodol, DS Bender): 335-46. American Psychiatric Publishing, 2005

43 Livesley WJ. A framework for an integrated approach to treatment. In Handbook of Personality Disorders: Theory, Research and Treatment: 570-600. Guilford, 2001.

44 Dawson D. The therapeutic relationship. In Clinical Assessment and Management of Severe Personality Disorders (ed PS Links): 161-74. American Psychiatric Publishing, 1996.

45 Aviram RB, Hellerstein DJ, Gerson J, Stanley B. Adapting supportive psychotherapy for individuals with borderline personality disorder who self-injure or attempt suicide. J Psychiatr Pract 2004; 10: 145-55.

46 Hellerstein DJ, Rosenthal RN, Pinsker H, Samstag LW, Muran JC Winston A. A randomized prospective study comparing supportive and dynamic therapies. Outcome and alliance. J Psychother Pract Res 1998; 7 261-71.

47 Piper WE, Joyce AS, McCallum M, Azim HF. Interpretive and supportive forms of psychotherapy and patient personality variables. J Consult Clin Psychol 1998; 66: 558-67.

48 Rockland LH. A review of supportive psychotherapy, 1986-1992. Hosp Community Psychiatry 1993; 44: 1053-60.

49 Holmes J. Supportive psychotherapy. The search for positive meanings. Br J Psychiatry 1995; 167: 439-45.

50 Tyrer P. Nidotherapy: a new approach to the treatment of personality disorder. Acta Psychiatr Scand 2002; 105: 469-71.

51 Tyrer $P$, Sensky T, Mitchard S. Principles of nidotherapy in the treatment of persistent mental and personality disorders. Psychother Psychosom 2003; 72: 350-6.

52 Hennessey M, McReynolds CJ. Borderline personality disorder: psychosocial considerations and rehabilitation implications. Work 2001; 17: 97-103.

53 Appelbaum AH, Munich RL. Reinventing moral treatment: the effects upon patients and staff members of a program of psychosocial rehabilitation. Psychiatr Hosp 1986; 17: 11-9.

54 Zanarini MC, Frankenburg FR, Hennen J, Reich DB, Silk KR. Prediction of the 10-year course of borderline personality disorder. Am J Psychiatry 2006; 163: 827-32.

55 Gunderson JG, Bender D, Sanislow C, Yen S, Rettew JB, Dolan-Sewell R, et al. Plausibility and possible determinants of sudden 'remissions' in borderline patients. Psychiatry 2003; 66: 111-9. 
56 Fonagy $\mathrm{P}$, Bateman A. Progress in the treatment of borderline personality disorder. Br J Psychiatry 2006; 188: 1-3.

57 Dawson D, Macmillan H. Relationship Management of the Borderline Patient. Brunner Mazel, 1993.

58 Gunderson JG. Borderline Personality Disorder: A Clinical Guide. American Psychiatric Publishing, 2001.

59 Paris J. Personality Disorders Over Time. American Psychiatric Publishing 2003.

60 Lieb K, Zanarini MC, Schmahl C, Linehan MM, Bohus M. Borderline personality disorder. Lancet 2004; 364: 453-61.

61 Prosser D, Johnson S, Kuipers E, Szmukler G, Bebbington P, Thornicroft G. Mental health, 'burnout' and job satisfaction among hospital and community-based mental health staff. Br J Psychiatry 1996; 169: 334-7.

62 Onyett S, Pillinger T, Muijen M. Job satisfaction and burnout among members of community mental health teams. J Ment Health 1997; 6: 55-66
63 Tyrer P, Al Muderis O, Gulbrandsen D. Distribution of case-load in community mental health teams. Psychiatr Bull 2001; 25: 10-2.

64 Bateman AW, Fonagy P. Effectiveness of psychotherapeutic treatment of personality disorder. Br J Psychiatry 2000; 177: 138-43.

65 Gallop R, O'Brien L. Re-establishing psychodynamic theory as foundational knowledge for psychiatric/mental health nursing. Issues Ment Health Nurs 2003; 24: 213-27.

66 Sampson MJ. The challenges community mental health teams face in their work with patients with personality disorders. In Personality Disorder and Community Mental Health Teams: A Practitioner's Guide (eds M Sampson, R McCubbin, P Tyrer): 221-40. Wiley, 2006.

67 Krawitz R. Borderline personality disorder: attitudinal change following training. Aust N Z J Psychiatry 2004; 38: 554-9.

68 Hazelton M, Rossiter R, Milner J. Managing the 'unmanageable': training staff in the use of dialectical behaviour therapy for borderline personality disorder. Contemp Nurse 2006; 21: 120-30. 